\title{
El derecho internacional de los derechos culturales
}

FIGURAS REVISTA ACADÉMICA DE INVESTIGACIÓN

ISSN 2683-2917

Vol. 2, núm. 1, noviembre 2020-febrero 2021

https://doi.org/10.22201/fesa.figuras.2020.2.1

\section{Esta obra está bajo una licencia}

Creative Commons Atribución-NoComercial-

Compartirlgual 4.0 Internacional

\section{International Law of Cultural Rights}

https://doi.org/10.22201/fesa.figuras.2020.2.1.132

\section{(D) Erika Flores-Déleon}

Instituto Internacional de Derecho Cultural

y Desarrollo Sustentable, México

El ensayo revisa la reforma constitucional en materia cultural del año 2009 en la que se estableció que "toda persona tiene derecho al ejercicio de los derechos culturales"; también analiza su entrada en vigor en 2011 cuando se elevan a plenos derechos y libertades fundamentales.

\section{Introducción}

Los derechos culturales se encuentran reconocidos en el párrafo doceavo del artículo $4^{\circ}$ de la Carta Magna de los Estados Unidos Mexicanos, desde abril del 2009. Asimismo, desde la reforma constitucional en materia de derechos humanos publicada en el DoF en junio del 2011, el derecho internacional de los derechos culturales cobra rango constitucional; es por ello que damos cuenta de la importancia de la naturaleza jurídica de esta subcategoría del derecho internacional de los derechos humanos, en aras de que tanto la normatividad infra-constitucional como las políticas culturales estén apegadas a esta fuente internacional de Derecho interno. 
Una vez establecidos los bienes jurídicos tutelados por el derecho de la educación y el derecho de la cultura, haremos una compilación de los instrumentos jurídicos internacionales vinculantes más relevantes para el Estado mexicano en dichas materias que se integran al sistema normativo cultural como categorías esenciales del Derecho Cultural.

\section{Marco teórico y conceptual del Derecho Cultural}

El derecho internacional de los derechos humanos está inserto dentro del derecho internacional público, definido como la rama del Derecho que estudia las relaciones entre sujetos jurídicos internacionales.

Fue a partir de la Segunda Guerra Mundial que se comenzó a forjar, desde la comunidad internacional, un ordenamiento jurídico de carácter mundial de protección y promoción de los Derechos humanos, que contribuyó a convertir sus normas en obligatorias para los Estados y sus relaciones con los individuos y organizaciones de la sociedad civil, es a lo que la doctrina conoce como derecho internacional de los derechos humanos.

Por otro lado, cabe hacer la precisión de que el derecho internacional público surge de diversas fuentes, tales como el derecho consuetudinario y el derecho convencional. El primero consta de dos elementos, a saber: uno objetivo, el cual consiste en la repetición continuada de un comportamiento por parte de un sujeto determinado; y un elemento subjetivo, que consiste en la convicción del sujeto de estar realizando una conducta obligada a través de la repetición del acto concreto.

Por otro lado, el derecho convencional se refiere a las normas jurídicas internacionales positivizadas en instrumentos jurídicos de carácter vinculante para los Estados signatarios, tales como tratados internacionales, convenciones, cartas, pactos o protocolos.

Así, podemos definir el derecho internacional de los derechos culturales como un subsistema jurídico del derecho internacional de los derechos humanos compuesto por disposiciones de carácter internacional contenidas en instrumentos jurídicos que regulan el quehacer cultural, en donde se entiende como 'quehacer cultural' aquella actividad humana encaminada a estimular la creatividad, el intelecto y la identidad, como condición sine qua non para el libre desarrollo de la personalidad en el marco de la diversidad de expresiones culturales (Flores 2018, 23).

En efecto, existe una basta actividad normativa internacional de fuente convencional en materia de derecho cultural, así como diversas normas contenidas en instrumentos internacionales que, a pesar de no regular el derecho cultural, sí contienen disposiciones en la materia.

Otro término medular que debemos mencionar es el 'neo-constitucionalismo' (Comanducci 2009, 85), es decir, aquel modelo constitucional proveniente del nuevo paradigma en materia de derechos humanos en el cual México está inserto desde la entrada en vigor de las reformas constitucionales publicadas en el DOF el 6 y 10 de junio del 2011.

A partir de ahora, la estructura institucional creada por el orden político existente queda vinculada constitucionalmente a la tutela efectiva de los derechos (proposiciones ius-fundamentales) proclamados en la parte dogmática de la Constitución. En efecto, ahora la legitimación del Estado -como creación jurídica-, misma que se sustenta sobre la base de la estructura institucional creada por el mismo orden jurídico-político, tiene su fundamentación en hacer valer los derechos inalienables de toda persona -tanto en su esfera individual como colectiva-, es 
decir, en la efectividad de los derechos fundamentales (Flores 2019, 17).

En este sentido, el 'neo-constitucionalismo' consiste en que la actividad del Estado debe ajustarse al nuevo paradigma, lo cual conlleva la transformación de éste en un ente garante y facilitador del ejercicio y goce de los derechos humanos, pues, como hemos mencionado, la función primaria de todo acto de poder es la realización de los derechos fundamentales y el respeto a sus garantías, es decir, en dotar de efectividad a los derechos humanos. Es lo que se conceptualiza como 'constitucionalización del ordenamiento jurídico' (Guastini 2009, 49).

Dicho con otras palabras, las normas de grado jerárquicamente superior establecidas en el bloque de constitucionalidad, compuesto por la Constitución, la jurisprudencia constitucional, las normas de derechos humanos contenidas en tratados internacionales vinculantes y la jurisprudencia interamericana, son estándares mínimos sobre los que se legitima todo acto de poder, incluidas las disposiciones de rango infra-legal y actos de autoridad, tanto en su vertiente positiva -acciones- como negativa-omisiones (Flores 2019, 18).

Los derechos y libertades fundamentales, en términos ferrajolianos, son límites y vínculos jurídicos a toda actuación de todos los poderes, y de todo acto y omisión de toda autoridad. Los derechos fundamentales son derecho positivo que vincula directamente a todo poder y todo acto de autoridad (Ferrajoli 2014, 30).

Por 'garantías' entendemos las técnicas de tutela de los derechos fundamentales; éstas pueden ser primarias o secundarias, jurisdiccionales y no jurisdiccionales. Entendemos por garantías primarias las legales que prohíben acciones que constituyen una violación a un derecho, así como aquellas normas que obligan a comportamientos para que el derecho se cumpla; éstas comportan una obligación de prestación o prohibición de lesión de los derechos fundamentales; $y$, por garantías secundarias, las garantías jurisdiccionales - tanto nacionales como internacionales - que consisten en prever y aplicar determinadas sanciones cuando con la garantía primaria no se obtiene el resultado esperado. Las garantías secundarias surgen como mecanismo para reforzar las garantías primarias, funcionan sólo en caso de falta o incumplimiento de las mismas, y suponen la obligación de reparar o sancionar judicialmente las lesiones de los derechos, es decir, las violaciones a las garantías primarias (Ferrajoli 2004, 43).

En cuanto a las garantías no jurisdiccionales, son mecanismos de tutela de los derechos fundamentales en donde intervienen agentes externos al ámbito jurisdiccional; existe la posibilidad de accionar denuncias ante organismos de defensa de los derechos humanos -nacionales o internacionales-, medios de comunicación de masas, entre otros instrumentos que promueven el conocimiento y la sensibilidad como mecanismo de prevención (Flores 2018, 30).

En efecto, un derecho carece de garantías cuando no es protegido, ya sea por persistir lagunas o antinomias normativas (Ferrajoli 2014, 29), o aplicado, por ser la actuación de los poderes - públicos o privados- contraria a los derechos humanos. Tanto las lagunas como las antinomias deben ser colmadas y subsanadas, respectivamente, por las autoridades competentes.

Es decir, podemos tener derechos, pero no garantías cuando los derechos no cuentan con legislación de desarrollo, cuando la legislación de desarrollo es contraria a la efectiva protección de los derechos fundamentales, o cuando los actos u omisiones de autoridad distan de materializarse a la luz del nuevo estatuto constitucional de los derechos humanos (Flores 2019, 25). 
El 'garantismo' alude a la relación existente entre derechos fundamentales y garantías. Entendemos por garantismo al "conjunto de límites y vínculos impuestos a cualquier poder, idóneos para garantizar la máxima efectividad de todos los derechos y de todas las promesas constitucionales." (Carbonell 2005, 30)

El garantismo es sinónimo de estado constitucional de derecho; es decir, un sistema que toma el paradigma clásico del estado liberal y lo amplía en dos direcciones: por un lado, a todos los poderes, no sólo al judicial, sino también al legislativo y ejecutivo, y no sólo a los poderes públicos sino también a los privados; $y$, por otro, a todos los derechos, no sólo a los de libertad, sino también a los sociales, con las consiguientes obligaciones, además de las prohibiciones, a cargo de la esfera pública. (Ferrajoli 2014, 29)

Los derechos culturales (o derecho cultural, términos utilizados indistintamente para denotar un mismo sistema normativo) se encuentran reconocidos en el artículo $4^{\circ}$, párrafo doceavo de la Carta Magna de los Estados Unidos Mexicanos, desde abril del 2009.

\section{Todo derecho no basta con} ser proclamado, sino que debe ser
garantizado de manera efectiva
por el Estado.

Se entiende por 'derecho cultural' aquel sistema normativo compuesto por un conjunto de disposiciones contenidas en instrumentos jurídicos que regulan el quehacer cultural, en donde el 'quehacer cultural' resulta en aquella actividad humana dirigida a estimular la creatividad, el intelecto y la identidad como condición a la adquisición de herramientas que coadyuvan al libre desarrollo de la personalidad en el marco de la diversidad de las expresiones culturales (Flores 2018, 23). Como todo derecho, no basta con ser proclamado, sino que debe ser garantizado de manera efectiva por el Estado (Queralt 2012, 265).

En efecto, el derecho cultural es una disciplina especializada y emergente en la ciencia jurídica, cuestión que en un Estado constitucional y democrático de Derecho no da lugar a seguir siendo relegada, descuidada y subdesarrollada, sino impulsada, enriquecida y desarrollada, a partir de un marco epistémico, teórico y conceptual.

Como última precisión terminológica, utilizaremos indistintamente el término 'derecho cultural' y 'derechos culturales' para denotar el sistema normativo objeto de estudio que nos ocupa, el cual debe ser diferenciado del término 'derechos culturales', pues refiere al derecho de los pueblos originarios; y por 'derecho a la cultura', que abarca el derecho de las Bellas Artes, el progreso científico y los beneficios asociados a él (Flores 2018, 24).

Asimismo, al partir de los principios sobre los que se vertebran los derechos humanos, a saber: universalidad, interdependencia, indivisibilidad y progresividad, para su estudio, regulación e instrumentación, así como para su medición, evaluación y aplicación metodológica, lo agrupamos en nueve categorías esenciales.

Dichas categorías esenciales protegen bienes jurídicos indispensables para el pleno desarrollo de la personalidad. Su sistematización y pleno desarrollo normativo es relevante ya que los derechos culturales, al ser parte inherente al sistema universal de los derechos humanos, se tutelan y garantizan de forma íntegra o, por el contrario, se violan, ya que los derechos humanos no se pueden garantizar a medias, en cuyo caso se estaría conculcando.

El sistema normativo cultural, denominado Diagrama de Valor del Derecho Cultural, es el siguiente: 
1. Derecho de la educación.

2. Derecho de la cultura.

3. Derecho del patrimonio cultural.

4. Derechos de autor.

5. Derecho de los medios de comunicación y nuevas tecnologías.

6. Derecho de los pueblos originarios.

7. Derecho de la artesanía.

8. Derecho de los símbolos tanto nacionales como identitarios.

9. Derecho de la diversidad cultural.

\section{Núcleo fuerte y núcleo débil del derecho internacional de los derechos culturales}

El derecho internacional de los derechos culturales comprende el conjunto de instrumentos jurídicos internacionales suscritos por el Estado mexicano en materia de derecho cultural -es a lo que en los apartados siguientes denominamos regulación directa- o que, a pesar de regular otro tipo de materia sí contengan disposiciones en materia cultural -regulación indirecta.

En este mismo orden de ideas, esta fuente internacional de Derecho interno, según se desprende del artículo $1^{\circ}$ de la Constitución Política de los Estados Unidos Mexicanos tras la reforma publicada en materia de derechos humanos de junio del 2011, el conjunto de instrumentos jurídicos internacionales son compromisos asumidos por México ante la comunidad internacional y adquieren rango constitucional además de una aplicabilidad directa y fuerza vinculante para los tres poderes del Estado y para los tres órdenes de gobierno.

Para su estudio y sistematización subdividimos en dos vertientes, siendo ambos estándares mínimos para ser acatados por los países firmantes.
Por un lado, en cuanto a la normatividad, el conjunto de instrumentos internacionales jurídicamente vinculantes para el Estado mexicano son el núcleo fuerte; asimismo, denominamos núcleo débil o soft law al conjunto de instrumentos internacionales no vinculantes empero jurídicamente relevantes para la comunidad internacional (Flores 2018, 65).

Por otro lado, es fuente internacional de Derecho interno la jurisprudencia emanada de la Corte Interamericana de Derechos Humanos.

Después de estos antecedentes, en este ensayo haremos una compilación de la producción jurídica de carácter vinculante - núcleo fuerte o hard law - y no vinculante -núcleo débil o soft law- más relevante del derecho internacional de los derechos culturales de dos de las nueve categorías del derecho cultural: educación y cultura.

\section{Derecho internacional de los derechos culturales, vertiente educación}

El derecho de la educación, categoría esencial del derecho cultural, tutela los bienes jurídicos relacionados con la esfera cognitiva, científica, creativa, física, ética, estética, espiritual, social y familiar de la persona, elementos a estimular de forma equilibrada por ser la persona un ser integral (Flores 2018, 53).

A continuación se enlista la compilación de instrumentos ratificados por México en materia de educación; es decir, el derecho internacional de los derechos culturales vertiente educación, tanto su regulación directa como indirecta, sin olvidar que el Gobierno de los Estados Unidos Mexicanos, en aras de fortalecer la cooperación bilateral en el campo educativo y cultural ha suscrito diversos acuerdos de cooperación. 


\section{Regulación directa}

- Convención sobre la Orientación Pacífica de la Enseñanza. ${ }^{1}$

- Constitución de la Organización de las Naciones Unidas para la Educación, la Ciencia y la Cultura (UNESCO). ${ }^{2}$

- Carta de la Organización de Estados Americanos. ${ }^{3}$

- Convención Americana de los Derechos Humanos. ${ }^{4}$

- Pacto Internacional de los Derechos Económicos, Sociales y Culturales. ${ }^{5}$

${ }^{1}$ Clase de instrumento: Tratado internacional. Fecha de firma: 23 de diciembre de 1936. Fecha de entrada en vigor internacional: 16 de marzo de 1938. Vinculación de México: 16 de marzo de 1938 (Ratificación). Fecha de entrada en vigor para México: 16 de marzo de 1938. Dof: 17 de junio de 1938. Disponible en: https://bit.ly/3iNogP7 Revisado el 29 de septiembre, 2020.

2 Acta Final de la Conferencia de las Naciones Unidas para el Establecimiento de una Organización Educativa, Científica y Cultural. Cfr.https://bit.ly/3dcirg4 (20 de septiembre del 2016). Revisado el 29 de septiembre, 2020.

${ }^{3}$ Clase de instrumento: Tratado internacional. Fecha de firma: 30 de abril de 1948. Fecha de entrada en vigor internacional: 13 de diciembre de 1951. Vinculación de México: 23 de noviembre de 1948. Fecha de entrada en vigor para México: 13 de diciembre de 1951. Dof: 13 de enero de 1949. Disponible en: https://bit. ly/30P5T9v Revisado el 29 de septiembre, 2020.

${ }^{4}$ Clase de instrumento: Tratado internacional. Adopción: 22 de noviembre de 1969. Fecha de entrada en vigor internacional: 18 de julio de 1978. Vinculación de México: 24 de marzo de 1981 (Adhesión). Fecha de entrada en vigor para México: 24 de marzo de 1981. DoF: 7 de mayo de 1981. Disponible en: https://bit.ly/2SDsx07 Revisado el 29 de septiembre, 2020.

${ }^{5}$ Clase de instrumento: Tratado internacional. Adopción: 16 de diciembre de 1966. Fecha de entrada en vigor internacional: 3 de enero de 1976. Vinculación de México: 23 de marzo de 1981 (Adhesión). Fecha de entrada en vigor para México: 23 de junio de 1981. Dof: 12 de mayo de 1981. Disponible en: https://bit.ly/33G1wzh Revisado el 29 de septiembre, 2020.
- Protocolo Adicional a la Convención Americana sobre Derechos Humanos en materia de Derechos Económicos, Sociales y Culturales. ${ }^{6}$

- Tratado de la Organización del Convenio Andrés Bello de Integración Educativa, Científica, Tecnológica y Cultural. ${ }^{7}$

\section{Regulación indirecta}

- Convenio 169 sobre Pueblos Indígenas y Tribales en Países Independientes de la Organización Internacional del Trabajo. ${ }^{8}$

- La Convención sobre la Eliminación de la Discriminación Racial. ${ }^{9}$

${ }^{6}$ Clase de instrumento: Tratado internacional. Adopción: 17 de noviembre de 1988. Fecha de entrada en vigor internacional: 16 de noviembre de 1999. Vinculación de México: 16 de abril de 1996 (Ratificación). Fecha de entrada en vigor para México: 16 de noviembre de 1999. DOF: 1 de septiembre de 1998. Disponible en: https://bit. ly/30KkNO8 Revisado el 29 de septiembre, 2020.

${ }^{7}$ DECRETO Promulgatorio de la Organización del Convenio Andrés Bello de Integración Educativa, Científica, Tecnológica y Cultural, hecho en la ciudad de Madrid, España, el veintisiete de noviembre de mil novecientos noventa. Disponible en: https://bit.ly/3nuHbFd Revisado el 29 de septiembre, 2020.

8 Clase de instrumento: Tratado internacional. Fecha de firma: 27 de junio de 1989. Fecha de entrada en vigor internacional: 5 de septiembre de 1991. Vinculación de México: 5 de septiembre de 1990 (Ratificación). Fecha de entrada en vigor para México: 5 de septiembre de 1991. DOF: 24 de enero de 1991. Disponible en: https:// bit.ly/3nA2Dsy (23 de diciembre del 2016). Revisado el 29 de septiembre, 2020.

9 Clase de instrumento: Tratado internacional. Fecha de entrada en vigor internacional: 4 de enero de 1969. Vinculación de México: 20 de febrero de 1975 (Ratificación). Fecha de entrada en vigor para México: 20 de marzo de 1975. DoF: 13 de junio de 1975. Disponible en: https://bit.ly/3ddaWFN Revisado el 29 de septiembre, 2020. 
- Convención sobre la Eliminación de la Discriminación contra la Mujer. ${ }^{10}$

- Convención sobre los Derechos del Niño. ${ }^{11}$

- Protocolo Facultativo de la Convención sobre Derechos del Niño sobre la Venta de Niños, la Prostitución Infantil y la Utilización de los Niños en la Pornografía. ${ }^{12}$

- El Protocolo Facultativo de la Convención contra la Tortura y otros Tratos o Penas Crueles, Inhumanos o Degradantes. ${ }^{13}$

\section{Derecho internacional de los derechos culturales, vertiente cultura}

El derecho de la cultura protege los bienes jurídicos relacionados con la actividad creativa en las ramas de

${ }^{10}$ Clase de instrumento: Tratado internacional. Fecha de entrada en vigor internacional: 4 de enero de 1969. Vinculación de México: 20 de febrero de 1975 (Ratificación). Fecha de entrada en vigor para México: 20 de marzo de 1975. DOF: 13 de junio de 1975. Disponible en: https://bit.ly/36J4q8w Revisado el 29 de septiembre, 2020.

${ }^{11}$ Clase de instrumento: Tratado internacional. Fecha de firma: 20 de noviembre de 1989. Fecha de entrada en vigor internacional: 2 de septiembre de 1990. Vinculación de México: 21 de septiembre de 1990 (Ratificación). Fecha de entrada en vigor para México: 21 de octubre de 1990. DOF: 25 de enero de 1991. Disponible en: https:// bit.ly/3iIUaQ7 Revisado el 29 de septiembre, 2020.

${ }^{12}$ Clase de instrumento: Tratado internacional. Fecha de firma: 25 de mayo de 2000 . Fecha de entrada en vigor internacional: 18 de enero de 2002. Vinculación de México: 15 de marzo de 2002 (Ratificación). Fecha de entrada en vigor para México: 15 de abril de 2002. DOF: 22 de abril de 2002. Disponible en: https://bit. ly/36LMHoj Revisado el 29 de septiembre, 2020.

${ }^{13}$ Clase de instrumento: Tratado internacional. Fecha de firma: 18 de diciembre de 2002.Fecha de entrada en vigor internacional: 22 de junio de 2006 . Vinculación de México: 11 de abril de 2005 (Ratificación). Fecha de entrada en vigor para México: 22 de junio de 2006. DOF: 15 de junio de 2006. Disponible en: https://bit. ly/30MHUrI Revisado el 29 de septiembre, 2020. las bellas artes, ciencia, tecnología e innovación, con pleno respeto a la libertad creativa e investigación científica.

En cuanto a la actividad creativa, ésta regula el entorno para que sea favorable y propicio; los productos generados a través de esta actividad protegen tanto el elemento subjetivo como el elemento objetivo de la cadena del quehacer cultural - que comienza con el creador hasta llegar al espectador final de productos culturales-, es decir, que comprende todos los canales para su efectiva producción, distribución, difusión y disfrute.

En lo concerniente a la actividad creativa en las bellas artes, el bien jurídico protegido corresponde a las acciones realizadas con el fin de perseguir la belleza - mas no la fama ni el dinero, aunque éstas sean consecuencia de aquella. La belleza se manifiesta en diversas expresiones artísticas, tales como la literatura, artes plásticas y visuales, música de arte, artes escénicas, danza, fotografía, arquitectura y cine de arte.

\section{La recreación, el entretenimiento y diversión a través de lo trivial o banal no es un derecho humano.}

En cuanto a la actividad creativa en la vertiente de la investigación científica, el bien jurídico tutelado es la preservación y desarrollo armónico de la vida (la raza humana y el entorno que la rodea) en cuanto a la ciencia, tecnología e innovación, tanto en su forma teórica como aplicada, así como de la normatividad que regula los avances y beneficios del progreso científico y sus aplicaciones.

Obsérvese que la recreación, el entretenimiento y diversión a través de lo trivial o banal no es un derecho 
humano. En efecto, ni el espectáculo ni la farándula deben ser financiados con recursos públicos por tener un fin meramente económico y comercial, mas no trascendental para el desarrollo cultural humano tanto individual como colectivo, base previa para el desarrollo sustentable.

A continuación se encuentran enlistados los instrumentos ratificados por México en materia de cultura, a saber, el derecho internacional de los derechos culturales, vertiente cultura.

\section{Regulación directa}

- Convención sobre Facilidades a Exposiciones Artísticas de $1936 .^{14}$

- Constitución de la Organización de las Naciones Unidas para la Educación, la Ciencia y la Cultura (UNESCO).

- Acta Constitutiva de la Asociación de Estados Iberoamericanos para el Desarrollo de las Bibliotecas Nacionales de los Países de Iberoamérica (ABINIA). ${ }^{15}$

- Convención sobre la Protección y la Promoción de la Diversidad de las Expresiones Culturales. ${ }^{16}$

${ }^{14}$ Decreto promulgatorio publicado en el DoF el 20 de mayo de 1938. Disponible en: https://bit.ly/36PE7NV Revisado el 29 de septiembre, 2020.

${ }^{15}$ Decreto promulgatorio publicado en el DoF el 31 de diciembre de 1969. Disponible en: https://bit.ly/34APS8c Revisado el 29 de septiembre, 2020.

${ }^{16}$ Clase de instrumento: Tratado internacional. Fecha de firma: 20 de octubre de 2005. Fecha de entrada en vigor internacional: 18 de marzo de 2007. Vinculación de México: 5 de julio de 2006 (Ratificación). Fecha de entrada en vigor para México: 18 de marzo de 2007. DOF: 26 de febrero de 2007. Disponible en: https://bit. ly/2IeB8EI Revisado el 29 de septiembre, 2020.

\section{Regulación indirecta}

- Carta de las Naciones Unidas. ${ }^{17}$

- Carta de la Organización de los Estados Americanos. $^{18}$

- Pacto Internacional de los Derechos Económicos, Sociales y Culturales.

- Protocolo Adicional a la Convención Americana de Derechos Humanos.

- Convención Internacional sobre la Eliminación de Todas las Formas de Discriminación Racial.

- Convención sobre la Eliminación de todas las Formas de Discriminación a la Mujer.

- Convención sobre los Derechos del Niño.

- Convención Internacional sobre la Protección de los Derechos de los Trabajadores Migratorios y sus Familias.

- Convención sobre los Derechos de las Personas con Discapacidad.

\section{Conclusiones}

Como hemos observado, el nuevo modelo jurídico cultural vigente desde junio del 2011 en los Estados Unidos Mexicanos implica accionar cambios sustantivos tanto en la legislación como en las políticas

${ }^{17}$ Clase de instrumento: Tratado internacional. Fecha de firma: 26 de junio de 1945. Fecha de entrada en vigor internacional: 24 de octubre de 1945. DOF: 17 de octubre de 1945. Fecha de entrada en vigor para México: 7 de noviembre de 1945 (Ratificación). Disponible en: https:// bit.ly/30MZeMY Revisado el 29 de septiembre, 2020.

${ }^{18}$ Clase de instrumento: Tratado internacional. Fecha de firma: 30 de abril de 1948. Fecha de entrada en vigor internacional: 13 de diciembre de 1951. Vinculación de México: 23 de noviembre de 1948. Fecha de entrada en vigor para México: 13 de diciembre de 1951. DOF: 13 de enero de 1949. Disponible en: https://bit.ly/2SG6bLj Revisado el 29 de septiembre, 2020. 
culturales, donde sean armonizadas así como fundamentadas y motivadas, respectivamente, en el derecho internacional de los derechos culturales que, al ser fuente internacional de Derecho interno, cobra rango constitucional, aplicabilidad directa y fuerza vinculante para los tres poderes del Estado y para los tres órdenes de gobierno.

Desafortunadamente, han transcurrido once años desde la constitucionalización de los derechos culturales como sistema normativo, así como nueve años desde la reforma constitucional en materia de derechos humanos y los derechos culturales, entendidos como derechos humanos, persisten regulados de forma fragmentada y dispersa. Por otro lado, ni la legislación ni las políticas culturales han sido armonizadas ni sistematizadas; no se cuenta con marcos conceptuales o teóricos, metodología ni indicadores que den cuenta del avance de la implementación e instrumentación de los derechos culturales bajo el enfoque garantista de los derechos humanos.

\section{Es menester trazar una hoja de ruta hacia la plena efectividad de los derechos culturales de todas y cada una de las personas, grupos, organizaciones y colectividades que integran el quehacer cultural.}

Es menester trazar una hoja de ruta - a mediano y largo plazo - desde un enfoque sistémico e ius-humanista hacia la plena efectividad de los derechos culturales de todas y cada una de las personas, grupos, organizaciones y colectividades que integran el quehacer cultural, en aras de cesar la perpetración, por parte de los poderes públicos, de violaciones sistemáticas por omisión de los derechos y libertades que asisten al sector cultural.

\section{Referencias}

Ángulo, Geofredo. 2015. Teoría contemporánea de los derechos humanos. Elementos para una reconstrucción sistémica. España: Dykinson S. L.

Asuaga, Carolina, coord. y ed. 2009. "El Derecho de la Cultura como nueva especialidad jurídica." En Un encuentro no casual: Cultura, Ciencias Económicas y Derecho. Uruguay: Fundación de Cultura Universitaria.

Becerra, Manuel. 2012. La recepción del derecho internacional en el derecho interno. 2. ${ }^{\mathrm{a}}$ ed. México: Universidad Nacional Autónoma de México, Instituto de Investigaciones Jurídicas.

Carbonell, Miguel, ed. 2007. Teoría del neoconstitucionalismo. Ensayos escogidos. Madrid: Trotta-UNAM, Instituto de Investigaciones Jurídicas.

Carbonell, Miguel y Pedro Salazar, eds. 2005. Garantismo. Estudios sobre el pensamiento jurídico de Luigi Ferrajoli. Madrid: Trotta-UNAM, Instituto de Investigaciones Jurídicas.

Comanducci, Paolo. 2009. "Formas de (neo) constitucionalismo: un análisis metateórico." En Neoconstitucionalismo(s). Coordinado por Miguel Carbonell. 4. ${ }^{\mathrm{a}}$ ed. Madrid: Trotta.

Ferrajoli, Luigi. 2004. Derechos y garantías. La ley del más débil. 4. ${ }^{\mathrm{a}}$ ed. Madrid: Trotta.

Ferrajoli, Luigi. 2014. La democracia a través de los derechos. El constitucionalismo garantista como modelo teórico y como proyecto político. Traducido por Perfecto Andrés Ibáñez. España: Trotta.

Flores, Erika. 2018. Introducción al derecho cultural. 1. ${ }^{\text {er }}$ tomo de la Colección "Lecciones de Derecho Cultural". Barcelona: Atelier Libros Jurídicos e IDC Cultura, Instituto Internacional de Derecho Cultural y Desarrollo Sustentable.

Flores, Erika. 2019. El nuevo paradigma constitucional de los derechos culturales. $4 .^{\circ}$ tomo de la Colección "Lecciones de Derecho Cultural". Barcelona: Atelier Libros Jurídicos e IDC Cultura, Instituto Internacional de Derecho Cultural y Desarrollo Sustentable.

Guastini, Riccardo. 2009. "La constitucionalización del ordenamiento jurídico: el caso italiano." En Neoconstitucionalismo(s). Coordinado por Miguel Carbonell. 4. $^{\mathrm{a}}$ ed. Madrid: Trotta.

Queralt, Argelia. 2012. "Garantías de los derechos y libertades." En Tomo XXII Esquemas de derecho constitucional. Coordinado por Itziar Gómez. 3 . $^{\mathrm{a}}$ edición. Valencia: Tirant lo Blanch. 